\title{
PROKLA-Redaktion
}

\section{Editorial: Ressourcenkonflikte}

Wieder einmal stehen die Ölpreise auf Rekordhöhe und schüren Befürchtungen, die schwachen Ansätze einer konjunkturellen Erholung könnten durch hohe Energiekosten abgewürgt werden. Nicht zuletzt daran wird die Bedeutung der natürlichen Ressourcen für die Entwicklung der kapitalistischen Ökonomie deutlich. Auch bei dem im vergangenen Jahr von den USA und ihren Alliierten geführten Krieg gegen den Irak waren sich die meisten Kommentatoren einig, dass die Ölinteressen der USA eine maßgebliche Rolle gespielt haben. Ebenso geht es in den „neuen Kriegen“, die nach dem Ende der Blockkonfrontation vor allem in den zerfallenden Staaten Afrikas geführt werden, häufig um die Kontrolle von Bodenschätzen.

Den natürlichen Ressourcen kommt in mehrfacher Hinsicht eine besondere Rolle zu. Einerseits sind sie nicht beliebig vermehrbar, so dass ihre Endlichkeit schon vor Jahrzehnten zu Diskussionen über die „Grenzen des Wachstums“ führte. Vor allem aber sind sie im Unterschied zu industriell produzierbaren Gütern ortsgebunden. Ihre Ausbeutung und Verwertung setzt die Kontrolle über dieses Territorium und die entsprechenden Transportwege voraus, was die Grundlage einer ganzen Reihe von Konflikten liefert. Bereits in den klassischen Imperialismustheorien wurden derartige Fragen verhandelt. Allerdings geht es heute nicht nur um die physischen Räume, sondern auch um die funktionalen Räume des Weltmarkts, um die Beherrschung der Preisbildung und der Faktu- rierung der Ressourcen. Vor allem durch den Irakkrieg wurde die Frage nach dem Verhältnis von Globalisierung und Imperialismus erneut aufgeworfen (vgl. dazu PROKLA 133, Dezember 2003, Imperialistische Globalisierung).

Ressourcenkonflikte, die häufig das Potential zu einem militärisch ausgetragenen Konflikt haben, werden im 21. Jahrhundert wahrscheinlich keineswegs abnehmen, sie werden eher zunehmen. Dabei kann es sich um Konflikte von ganz unterschiedlicher Struktur handeln. So ist nicht nur Öl, sondern auch Wasser eine zunehmend umstrittene Ressource. Bereits jetzt gibt es erhebliche Wasserkonflikte zwischen der Türkei, Syrien und dem Irak, zwischen Israel und seinen Nachbarn sowie zwischen Ägypten und dem Sudan und Äthiopien. Die Erschöpfung oder Vernichtung landwirtschaftlicher Böden durch zunehmende Versteppung (welche ihre Ursache unter anderem im Klimawandel haben dürfte) führte bereits $\mathrm{zu}$ Millionen von Umweltflüchtlingen, die in Städte oder andere Länder auswandern und dort die sozialen Konflikte verschärfen. Häufig führen diese Fluchtbewegungen auch zu erheblichen politischen Spannungen zwischen benachbarten Ländern.

Allerdings dürften auch in Zukunft die Konflikte um Erdöl als den Energieträger Nummer Eins des gegenwärtigen Kapitalismus von besonderem Gewicht sein. Während sich die Vorräte an fossilen Brennstoffen in diesem Jahrhundert ihrer Erschöpfung nähern, wächst gleichzeitig der Verbrauch an Erdöl immer weiter an: 
Länder wie China, deren industrielle Entwicklung mit hohem Tempo vorangeht, haben ihren Ölverbrauch bereits bedeutend erhöht und werden ihn mit Sicherheit noch weiter steigern; auf der andere Seite erfolgen Energiesparmaßnahmen in vielen entwickelten Ländern, vor allem in dem größten Verbraucherland, den USA, nur sehr zögerlich. Zugleich hat der Verbrauch der fossilen Energieträger eine erhebliche Belastung der Atmosphäre zur Folge, deren klimaverändernde Wirkungen man bereits spüren kann. Einen Überblick über diese Konflikte und ihre Auswirkungen gibt Jürgen Scheffran in seinem Artikel.

Die Ausbeutung von Rohstoffen hat nur in den seltensten Fällen zur positiven Entwicklung eines Landes beigetragen. In der Regel waren nicht trotz, sondern wegen des Ressourcenreichtums eines Landes seine Unterentwicklung die Folge. Beispiele sind erdölreiche Länder wie Nigeria, Venezuela, Mexiko, etc. Das Problem wird als „Holländische Krankheit“ in der Ressourcenökonomie diskutiert. Wie diese Mechanismen im Einzelnen funktionieren, wird in diesem $\mathrm{Heft}$ an zwei ganz unterschiedlichen Fällen untersucht: Alberto Acosta schildert die Entwicklung Ecuadors, die zunächst in durchaus positiven Bahnen verlief. Allerdings wurden im Verlauf der Schuldenkrise (und Schulden in erheblichem Ausmaße konnte Ecuador nur aufgrund seines Öls aufnehmen) aufgrund der vom IWF und den Gläubigern erzwungenen „Strukturanpassungen“ gerade die für die breiteren Schichten der Bevölkerung erreichten Verbesserungen $\mathrm{zu}$ einem großen Teil wieder zunichte gemacht. Jörn Thielman zeigt den „Fluch von Öl und Gas“ in Algerien auf. Dieser bescherte Algerien nicht nur einen überaus brutalen Krieg durch die Kolonialmacht Frankreich, auch nach der Unabhängigkeit blieb die erhoffte ökonomische Entwicklung weitgehend aus.

Für die Kapitalakkumulation entscheidend sind gegenwärtig aber nicht nur Bodenschätze und Energieträger, sondern zunehmend auch genetische Ressourcen. Die Fortschritte der Biotechnologie ermöglichen heute weitgehende Eingriffe ins genetische Material z.B. des Saatgutes. Dazu muss allerdings ein breites Spektrum der verschiedenen Arten vorhanden und - um dessen Verwertung zu ermöglichen - müssen die Eigentumsrechte daran gesichert sein. Bereits in PROKLA 129 (Dezember 2002) wurden dieses Thema von Christoph Görg und Ulrich Brand in ihrem Beitrag „Konflikte um das grüne Gold der Gene" diskutiert. Im vorliegenden Heft untersucht Joscha Wullweber den veränderten Zugriff auf das Saatgut und neue Formen der „Inwertsetzung" vor dem Hintergrund des Übergangs vom Fordismus zum Postfordismus. Einen anderen Fall der Verwertung genetischer Ressourcen diskutieren Ulrich Petschow und Anita Idel in ihrem Beitrag zum „globalen Huhn“. Staatliche Forschungsförderung, „Leistungssteigerung“ des Huhns durch Hybridisierung, dessen Standardisierung und unterschiedliche Wege der ökonomischen Konzentration gingen zunächst in den USA Hand in Hand. Dabei wurde ein - zumindest für die führenden Konzern - äußerst erfolgreiches Produktions- und Vertriebsmodell hervorgebracht und auch auf zahlreiche andere Länder übertragen. Allerdings birgt dieses Modell erhebliche Risiken für den Weiterbestand der genetischer Vielfalt des Huhns.

$$
* * *
$$

Außerhalb des Heftschwerpunkts wird die in PROKLA 133 aufgenommene Diskussion über Globalisierung und Imperialismus fortgesetzt. Stephen Gill antwortet auf den dort veröffentlichten Beitrag von Immanuel Wallerstein, der die US-amerikanische Hegemonie bereits auf einem stark absteigenden Ast angekommen sah. Demgegenüber stellt Gill die nach wie vor vorhandenen transnationalen ökonomischen und vor allem politischen Kapazitäten US-amerikanischer Macht heraus. 
Susanne Soederberg untersucht eine bislang wenig beachtete Wendung in der US-amerikanischen Entwicklungspolitik unter George W. Bush, das Millenium Challenge Account: dabei wird die Zahlung von Fördergeldern an die ärmsten und vom Weltmarkt weitgehend ausgeschlossenen Staaten unmittelbar an ,gutes Regieren“" und eine wirtschaftsliberale Politik gebunden.
In der im letzten Heft neu eingeführten Rubrik „Einsprüche“ setzt sich Ulrich Busch kritisch mit den neuesten Diskussionen über die ökonomische Entwicklung in Ostdeutschland und deren Auswirkungen auf die gesamtdeutsche Wirtschaft auseinander.

\section{PROKLA 136: Umbrüche des Sozialstaats (September 2004)}

Auch unter der rot-grünen Regierung wird, wie schon bei ihren Vorgängern unter immer neuen Etiketten ein Abbau sozialer Sicherungen betrieben, gleichgültig, ob es sich um die faktische Abschaffung der Arbeitslosenhilfe und verschärfte Zumutbarkeitsregeln für Arbeitslose handelt, eine stärkere Belastung der Patienten durch Praxisgebühr und Zuzahlungen oder die Absenkung des Rentenniveaus. In anderen europäischen Ländern findet Ähnliches statt, so dass sich die Frage stellt, ob man überhaupt von einem „europäischen Sozialmodell“ sprechen kann, wie dies in der Vergangenheit als Kontrastierung zur neoliberalen Marktorientierung geschehen ist. Ist der Klassenkompromiss, der den sozialstaatlichen Regelungen zugrunde lag, am Ende? Haben sich insbesondere die Mittelklassen vom sozialstaatlichen Modell abgewendet, das sie ihre Interessen am Markt besser befriedigt sehen? Oder sind es tatsächlich die Zwänge der Weltmarktkonkurrenz, die für sozialstaatliche Regelungen keinen Platz mehr lassen? Bei aller Kritik am Sozialabbau sollte nicht vergessen werden, dass der Sozialstaat erhebliche disziplinierende Wirkungen auf die Arbeitskräfte entfaltete und stets auch bestimmte Genderregime festschrieb. Die jüngsten „Reformen“ führen nicht nur zu einer Verminderung der materiellen Leistungen, sie verstärken auch diese disziplinierende Unterwerfung. Welches sind die Perspektiven des stattfindenden Umbaus? Und welche Perspektiven hat der mehr oder weniger starke Widerstand, den diese Umbrüche in den verschiedenen europäischen Ländern erfahren?

\section{PROKLA 137: Bildung und Ausbildung (Dezember 2004)}

Die Feststellung, dass in Deutschland Bildung und Bildungssysteme in einem kritischen Zustand sind, ist inzwischen zum Gemeinplatz geworden. Politiker aller Couleur fordern Abhilfe und mehr Geld für die Bildung. Um was für eine Bildung es dabei gehen soll, wird aber genauso wenig diskutiert, wie der Einfluss, den etwa die im Welthandelsabkommen GATS vorgesehene Liberalisierung des internationalen Handels mit Dienstleistungen auf die Träger von Bildungs- und Ausbildungseinrichtungen haben wird. Ausbildungsangebote werden noch weit mehr zur (auf dem Weltmarkt gehandelten) Ware werden, als dies bisher der Fall ist. Bildungsinstitutionen (und deren Export) werden sich zu einer keineswegs unbedeutenden Anlagesphäre von Kapital entwickeln. Die längst angelaufene Umstrukturierung sämtlicher Bildungsinstitutionen und ihre vielfältigen ökonomischen und sozialen Konsequenzen sollen im Mittelpunkt dieses Heftes der PROKLA stehen. 